\title{
LA LEY DE SEGUROS URUGUAYA NO. 19.678 DE 26/10/2018
}

\author{
ANDREA SIGNORINO BARBAT* \\ Fecha de recepción: 1 de noviembre de 2021 \\ Fecha de aceptación: 15 de noviembre de 2021 \\ Disponible en línea: 30 de diciembre de 2021 \\ Para citar este artículo/To cite this article
}

Signorino BAbat, Andrea. La ley de seguros Uruguaya No 19.678 de 26/10/2018, 55 Rev. Ibero-Latinoam.Seguros, 235-258 (2021). https://doi.org/10.11144/Javeriana.ris55.ldsu

doi:10.11144/Javeriana.ris55.ldsu

\footnotetext{
* Abogada, Traductora Pública, Universidad de la República Oriental del Uruguay. Postgrado en Gerencia y Habilidades gerenciales, Universidad ORT y de la Empresa. Doctoranda por la Universidad de Salamanca. Secretaria General de AIDA- Mundial (Association Internationale du Droit des Assurances), Secretaria académica internacional AIDA-Uruguay, Presidente Grupo internacional Nuevas Tecnologías, Prevención y Seguros en AIDA Ibero Latinoamérica, Vicepresidente Grupo internacional Principios generales del contrato de seguros en AIDA Mundial. Miembro Comisión Directiva de la Asociación uruguaya de derecho marítimo.

Profesora de grado y postgrado en seguros en Universidad de Buenos Aires, Pontificia Católica de Chile, Universidad Católica del Uruguay, Universidad de Salamanca, España. Profesora y Directora académica postgrado Internacinal de derecho de seguros en Universidad de Montevideo. Asesora legal y técnica, experta en seguros y reaseguros. andreasignorino@gmail.com - www.andreasignorino.com.uy
} 


\section{RESUMEN}

En la República Oriental del Uruguay, la Ley 19.678 vigente desde el 19 de noviembre de 2018, actualizó nuestra legislación sobre seguros. Se trata de la última Ley de seguros sancionada en Latinoamérica. La Ley refiere no solamente al contrato de seguros sino también a otros aspectos relacionados con la materia y el mercado asegurador. Se trata de una Ley especial sobre seguros, que moderniza las disposiciones que sobre éstos contiene nuestro Código de Comercio de 1865.

La mencionada Ley, publicada como "Aprobación de modificaciones en el marco legal del mercado de seguros", constituye un verdadero hito en el país pues sin dudas, contiene novedades de gran impacto en el contrato de seguros y en el mercado asegurador uruguayo.

En este artículo recorreremos en forma general la ley, para dar una primera aproximación de sus novedades al lector.

Palabras Clave: ley, especial, seguros, mercado, Uruguay

\section{ABSTRACT}

In the República Oriental del Uruguay, the Law No 19.678 in force since November 19, 2018, updated our insurance legislation. It is the last insurance law passed in Latin America. The Law refers not only to the insurance contract but also to other aspects related to the matter and the insurance market. It is a special law on insurance, which modernizes the provisions on insurance contained in our Commercial Code of 1865.

The Law, published as "Approval of modifications in the legal framework of the insurance market", constitutes a true milestone in the country since it undoubtedly contains novelties of great impact in the insurance contract and in the Uruguayan insurance market.

In this article we will go through the law in general, to give a first approximation of its news to the reader.

Keywords: law, special, insurance, market, Uruguay

SUMARIO: 1. INTRODUCCIÓN; 2. ESTRUCTURA DE LA LEY; 3. PRINCIPALES NOVEDADES 3.1. Naturaleza y alcance de la Ley; 3.2. Definición del contrato de seguro; 3.3. Perfeccionamiento del contrato; 3.4. Contenido de la póliza. Mención al intermediario; 3.5. Entrega de la póliza. Plazos y medios; 3.6. Renovación automática o prórroga del seguro; 3.7. Pluralidad de seguros; 3.8. Rescisión del contrato; 3.9. Agravamiento del riesgo; 3.10. Plazos para denuncia del siniestro y otros; 3.11. Prescripción. Registro de Seguros de Vida; 3.12. Disposiciones sobre ramas y tipos de seguros; 4. OTRAS DISPOSICIONES; 4.1. Reaseguros (capítulo IV); 4.2. Reglas de derecho internacional privado (capítulo V); 4.3. Denominación de empresas de seguros (capítulo VI); 4.4. Temas técnicos (capítulos VII y IX); 4.5. Seguro Obligatorio automotor - SOA (capitulo VIII); 4.6. Base de datos; 4.7. Derogaciones y sustituciones. Reserva de mercado (capitulo IX); 4.8. Disposiciones transitorias (capitulo XII); BIBLIOGRAFÍA 


\section{INTRODUCCIÓN}

Preliminarmente, cabe decir que en la República Oriental del Uruguay, el 8 de noviembre de 2018 se publicó en el Diario oficial, la Ley 19.678 que actualiza nuestra legislación sobre seguros. ${ }^{1}$ Se trata de la última Ley de seguros sancionada en Latinoamérica.

La Ley refiere no solamente al contrato de seguros sino también a otros aspectos relacionados con la materia y el mercado asegurador. Se trata de una Ley especial sobre seguros, que moderniza las disposiciones que sobre éstos contiene nuestro antiguo pero sabio, Código de Comercio de 1865.

La mencionada Ley, publicada como "Aprobación de modificaciones en el marco legal del mercado de seguros", constituye un verdadero hito en el país pues sin dudas, contiene novedades que han tenido y tendrán un impacto importante en el contrato de seguros y en el mercado asegurador uruguayo.

Por un lado, la Ley es de orden público, es decir que no pueden pactarse cláusulas que contradigan o modifiquen lo que la ley estipula, salvo cuando la propia ley habilita al pacto en contrario o cuando se trate de cláusulas más beneficiosas para el asegurado.

Por supuesto, para pactar en contario, o mejor dicho pactar en forma diferente a lo estipulado en la ley, deberá tenerse en cuenta el principio de buena fe, tan valorado en el contrato de seguros, y no vulnerar derechos de los asegurados.

La Ley trae novedades y cambios con respecto a la legislación anterior contenida en el Código de Comercio, e incluso con respecto a ciertas condiciones de póliza actuales.

Por solo mencionar algunos de estos cambios o novedades, el contrato de seguros pasa de ser solemne a consensual, existiendo plazos para que el asegurado se pronuncie sobre si las condiciones de póliza se ajustan a los términos de la solicitud aceptada; se establecen plazos para la denuncia del siniestro, la liquidación del daño y el pago del siniestro; la ley trae disposiciones precisas sobre el agravamiento del riesgo y sus consecuencias existiendo o no siniestro; se modifican los plazos de prescripción, siendo ahora diferentes en seguros de daños y para personas; existen condiciones específicas para ciertas ramas de seguros, regulándose los seguros de responsabilidad civil y en nueva forma, los agrícolas; se establece un Registro de Seguros de Vida que supone nuevos deberes de información en cabeza del asegurador.

Esto entre otras muchas novedades, sin pensar que, además, deberán reglamentarse varios aspectos legales.

Del lado del asegurado, este Cuenta ahora con un marco jurídico protector, que no puede ser vulnerado por las condiciones contractuales. Asimismo, la ley le impone obligaciones y cargas que debe cumplir.

1 Vigente desde el 19 de noviembre de 2018 


\section{ESTRUCTURA DE LA LEY}

La Ley cuenta con 135 artículos, distribuidos en los siguientes Capítulos y Secciones:

CAPÍTULO I-DEL CONTRATO DE SEGUROS

Sección I Disposiciones Generales

Sección II Del riesgo

Sección III De la póliza

Sección IV Obligaciones de las partes

Sección V Del siniestro

Sección VI Del incumplimiento

Sección VII De la prescripción

CAPÍTULO II-SEGUROS DE DAÑOS PATRIMONIALES

Sección I Disposiciones Generales

Sección II Seguros de incendios

Sección III Seguros de Responsabilidad Civil

Sección IV Seguros de hurto

Sección V Seguros de transporte

Sección VI Seguros de riesgo agrícola

CAPÍTULO III -SEGUROS PARA LAS PERSONAS

CAPÍTULO IV -REASEGUROS

CAPÍTULO V- REGLAS DE DERECHO INTERNACIONAL PRIVADO

CAPÍTULO VI-DENOMINACIÓN DE EMPRESAS DE SEGUROS

CAPÍTULO VII- ACTIVOS Y RESERVAS EN MATERIA DE OBLIGACIONES PREVISIONALES

CAPÍTULO VIII -SEGURO OBLIGATORIO DE AUTOMOTORES

CAPITULO IX -SEGUROS DE ACCIDENTES DE TRABAJO Y ENFERMEDADES PROFESIONALES

CAPITULO X -BASE DE DATOS DE SEGUROS

CAPITULO X- DEROGACIONES Y SUSTITUCIONES

CAPITULO XII- DISPOSICIONES TRANSITORIAS 
En el aspecto estructural, cabe destacar que la Ley presenta dos partes bien diferenciadas: hasta el capítulo $\mathrm{V}$ inclusive, trata aspectos relacionados directamente al contrato de seguros; del capítulo VI en adelante: trata aspectos que tocan otros puntos relacionados al seguro, a la actividad aseguradora.

Esto posiblemente aprovechando la ocasión de legislar sobre temas de seguros lo cual no ocurre a menudo. La última ley integral sobre la temática aseguradora es de finales de octubre del año 1993 en ocasión de la sanción de la Ley No 16.426 sobre desmonopolización del mercado de seguros. Luego cabe destacar algunas leyes especiales como la de seguro obligatorio automotor de 2008.

\section{PRINCIPALES NOVEDADES}

\subsection{Naturaleza y alcance de la Ley}

El Capítulo I "Del contrato de seguros" contiene las disposiciones generales aplicables a todas las ramas de seguros.

En él, el articulo 1 trae novedades importantes.

Artículo $1^{\circ}$ (Naturaleza y alcance). La presente ley es de orden público y tiene por objeto regular las distintas modalidades del contrato de seguro, sin perjuicio de la aplicación de las leyes especiales que rijan seguros especificos, así como de las disposiciones de la ley $N^{o} 17.250$, de 11 de agosto del 2002, toda vez que el contrato implique una relación de consumo, en lo no previsto expresamente en la presente ley.

Sin perjuicio de la naturaleza de esta ley, serán válidas las cláusulas contractuales más beneficiosas para el asegurado

Como dijimos la ley es de orden público, es decir que el principio es que no pueden pactarse cláusulas que contradigan o modifiquen lo que la ley estipula.

Y esto es importante pues deberán adaptarse las pólizas a las condiciones legales.

Las condiciones de pólizas muchas veces amparadas en la autonomía de la voluntad, o sea en la posibilidad de pactar en forma diferente a lo que el Código estipulaba-pues el Código en lo que a seguros refiere no es de orden público, como lo es la actual ley-, solían contener disposiciones diferentes a la legislación contenida en el Código.

Esto no será posible ahora pues como dije, la ley 19.678 es de orden público, salvo cuando la propia ley permite el pacto en contrario o cuando se pacten condiciones más beneficiosas para el asegurado, aspecto que no siempre será fácil de dilucidar.

Por ejemplo, si la ley prevé un plazo de dos años de prescripción para seguros generales, o sea dos años para poder reclamar contados desde la aceptación o rechazo del siniestro, y en la póliza se pactan tres años, esto en apariencia parece más beneficioso para el asegurado y podría colocarse en las pólizas. 
Pero si pensamos que dicho plazo también favorece al asegurador, pues también tendrá tres años para reclamar, por ejemplo si constata que existió un fraude y pagó mal el siniestro, finalmente esta ampliación del plazo ¿es a favor de asegurado? ¿O es a favor de ambas partes? ¿Podrá entonces, pactarse? Como vemos no va a ser fácil saber cuándo alguna cláusula es más beneficiosa para el asegurado y por ello puede "pactarse" en el contrato.

Asimismo, cunado la ley admite el pacto en contrario, dado la consagración de un orden público de protección, entiendo que nunca podrá pactarse una disposición que disminuya las garantías que consagra la Ley, como mínimo legal garantizado.

El otro aspecto destacable de este artículo 1 es que prevé la aplicación de la Ley de protección al consumidor, cuando el contrato de seguros implique una relación de consumo.

Esto es importante pues la ley está estableciendo dos tipos de contrato de seguros, uno de consumo y otro de no consumo. Y esto significa que no siempre al contrato de seguros se le deber aplicar la Ley de defensa al consumidor.

¿Cuándo se le deberá aplicar? Cuando el asegurado sea un consumidor, lo cual a la luz de la ley 17.250 será cuando el asegurado sea el "destinatario final" de la cobertura del seguro, o sea cuando lo aproveche para sí, en su beneficio, y no lo integre a un proceso de transformación o producción o comercialización.

Incluso un mismo asegurado puede ser o no consumidor o destinatario final, frente a distintas coberturas de seguros. Por ejemplo, un fabricante de volantes de autos deportivos para exportar, será consumidor en su seguro de incendio de la fábrica, pues podría utilizarla con otro fines, pero no lo será en su seguro sobre la materia prima, pues contrata ese seguro para proteger la materia base de la mercadería que exporta, o sobre el seguro de vida que contrata en beneficio de su personal pues no es el destinatario final del beneficio de dicho seguro.

Asimismo, la ley de protección al consumidor se aplicará en todo lo no previsto en la ley de seguros, que es una ley especial, frente a la ley general del consumidor.

\subsection{Definición del contrato de seguro}

El artículo 2 de la Ley 19.678 tambien es importante pues aporta una definición amplia del contrato de seguros.

El texto del artículo es el siguiente:

Artículo $2^{\circ}$ (Contrato de seguro. Definición). El contrato de seguro es aquel por el cual una parte, el asegurador, se obliga mediante el cobro de un premio, a resarcir al tomador, al asegurado, al beneficiario o a un tercero, dentro de los límites pactados, los daños, pérdidas o la privación de un lucro esperado, o a pagar un capital, servir una renta o cumplir otras prestaciones convenidas entre las partes, para el caso de ocurrencia del evento cuyo riesgo es objeto de la cobertura. 
La prima es la prestación del tomador o asegurado. El premio incluye la prima más los impuestos, tasas y demás recargos.

En el contenido del artículo, se abarcan distintas modalidades de prestaciones que pueden estar a cargo del asegurador en caso de acaecer el riesgo cubierto.

Es común pensar que el seguro solamente tiene como contraprestación de parte del asegurador, en caso de acaecer el riesgo cubierto, el pago de una suma de dinero. Pero como bien refiere el artículo, por un lado, el asegurador puede obligarse a resarcir al tomador, al asegurado, al beneficiario o a un tercero, dentro de los límites pactados, los daños, pérdidas o la privación de un lucro esperado.

"Resarcir" de acuerdo al diccionario de la Real Academia española es indemnizar, reparar, compensar un daño, perjuicio o agravio, con lo cual es claro que la utilización aquí, del término resarcir refiere a los seguros de daños donde rige el principio indemnizatorio.

Recordemos que el principio indemnizatorio es el que indica que la indemnización a cargo del asegurador no puede superar el daño sufrido por el asegurado en el objeto asegurado o en su patrimonio, en la eventualidad de tener que reparar el daño causado a un tercero en los seguros de responsabilidad civil.

Además del daño, el principio indemnizatorio tiene la limitante del interés asegurable, es decir que la indemnización no puede exceder el interés asegurable, relación lícita de contenido económico, del asegurado sobre el objeto asegurado.

El artículo sin embargo, no se limita a indicar que el seguro busca este resarcimiento de los daños, pérdidas o la privación de un lucro esperado.También refiere a que el asegurador se obliga -puede obligar- a pagar un capital, servir una renta o cumplir otras prestaciones convenidas entre las partes.

O sea que la obligación del asegurador no consiste sólo en prestar una indemnización, lo cual es adecuado ya que si consignara sólo esto, sería una limitante pues el seguro de personas no es, para la mayoría de la doctrina, indemnizatorio, no reviste carácter indemnizatorio ${ }^{2}$.

El artículo 2 abre la puerta a la posibilidad que la obligación a cargo del asegurador pueda consistir en "otras prestaciones", al decir que el asegurador se obliga-se puede obligar-a cumplir otras prestaciones convenidas entre las partes.

Esto es un cambio esencial con respecto al régimen vigente en materia de seguros para personas, que parte de cómo se definía hasta hoy a los Seguros para personas en la normativa bancocentralista.

La nrmativa parece adherrse a la moderna clasificación tripartita del contrao de segutos en seguros de sumas, de indemizaic;on y de pestaciones.

\footnotetext{
2 Si se quiere ahondar en las posiciones existentes en doctrina sobre el caracter indemnizatorio o no del Seguro de vida, ver el libro de mi autoria”Los Seguros de Vida...” Cap.I, FCU, Montevideo, 2008.
} 
Al decir del Dr. Bataller Grau: "Efectivamente, un contrato de seguro puede contener tres clases de obligaciones del asegurador. Por ello se puede hablar de seguros de indemnización, de seguros de sumas y de seguros de prestación de servicio. Los primeros, y con mayor raigambre histórica, son los seguros de indemnización, que consisten en el abono de una cantidad de dinero, pero que solo puede concretarse tras el siniestro, pues la indemnización requiere la previa cuantificación del daño... En segundo lugar, los seguros de sumas, son aquellos cuya cuantía ya está determinada de antemano en el contrato, por lo que los problemas en sede de liquidación del siniestro se reducen sensiblemente. La cantidad en que se debe concretar la suma a abonar por el asegurador ha sido estimada por los contratantes de manera abstracta, por lo que una vez acontecido el siniestro, la prestación del asegurador se devenga de manera automática sin que existan condicionantes o límites que influyan sobre la suma que debe abonar el asegurador...Las terceras, únicamente reconocidas que no reguladas,--refiere la derecho español- comprometen al asegurador a la realización de un servicio. Y a nuestro juicio creemos que resulta inapelable que así deben calificarse algunas obligaciones derivadas del contrato de seguro.... Nos encontramos aquí ante una categoría con un amplio predicamento en la práctica, pero que cuenta con escasos esfuerzo en la decantación de una primigenia teoría general que nos permita concretar una mínima regulación, pues a nadie escapa que una obligación de hacer debe regirse de manera diferente a una obligación pecuniaria"³.

El artículo 2 de la Ley 19.678 reconoce que pueden existir otras prestaciones a cargo de la aseguradora, ya sea que ella sea las que los brinda o ya sea que garantice dicha prestación a través de una red de prestadores con contratos con la aseguradora a dichos efectos.

Con esto se abre la puerta para que en el futuro puedan quedar dentro del sistema asegurador otras coberturas que se manejan del punto de vista económico y negocial como un seguro pero que no son abarcados por las exigencias de la Superintendencia de Servicios Financieros, ni por el respaldo que posee un seguro, como ser los hoy inadecuadamente llamados "seguros"de salud en nuestro país, que en realidad no son sometidos a los contralores bancocentralistas aplicables a la actividad aseguradora.

Por otro lado, el artículo 2 analizado refiere a que por una parte está el asegurador que se obliga mediante el cobro de un premio a resarcir a la otra parte, el tomador, el asegurado, el beneficiario o el tercero, la prestación convenida dentro de los límites pactados.

En este punto, la referencia al tomador del seguro, resulta conveniente en la definición del contrato de seguros junto a la figura del asegurado ya que ambos pueden ser destinatarios de la prestación convenida.

Se trata de dos figuras que ocupan posiciones jurídicas diferentes en el contrato de seguros y con obligaciones y cargas también disímiles.

En cambio, las referencias al beneficiario y al tercero en una definición de seguros, resultan polémicas.

\footnotetext{
3 Bataller Grau, J. "La necesaria tipificación de nuevos contratos de seguro: servicios y smarts contracts" Temas de seguros y reaseguros -Universidad de Montevideo- en edición.
} 
Por un lado, el beneficiario no es en principio frente a quien el asegurador se obliga a resarcir los daños o a pagar el capital o la renta o a servir otras prestaciones pactadas, como dice el texto. No es la contraparte contractual del asegurador.

Por eso el asegurado puede cambiarlo cuantas veces quiera, ejerciendo su derecho de revocación, salvo que se trate de un beneficiario irrevocable, lo cual es la excepción.

Similar situación ocurre con el tercero. La norma parece aludir o bien al tercero a quien se cede los derechos a la prestación convenida o bien al tercero innominado en los seguros de responsabilidad civil.

En el primer caso, estamos ante un beneficiario, en general irrevocable, y por lo tanto aplica lo antes expresado respecto a estos, constituyendo una excepción.

Ahora bien, si se trata del tercero innominado de los seguros de responsabilidad civil, si bien en principio es el destinatario de la prestación, nunca es la contraparte contractual del asegurador y por lo tanto no debería figurar de esta forma en la definición del contrato.

En efecto, y por más que nos afiliemos a la posición doctrinaria que afirma que en este tipo de coberturas, el derecho a la indemnización es del tercero y no del asegurado, quien asegura su patrimonio contra las posibles deudas generadas por su responsabilidad civil es el asegurado, el tercero innominado nunca es la contraparte contractual del asegurador como parece aludir el artículo 2.

Esto resulta aún más claro en legislaciones, como la comentada Ley 19.678, que no admiten la acción directa del tercero en seguros de responsabilidad civil, salvo si se consagra en leyes especiales como en Uruguay, en la de seguro obligatorio automotor. Si el tercero no tiene acción directa contra el asegurador, menos aún puede ser la contraparte contractual del asegurador ni la parte con derecho a indemnización en el seguro de responsabilidad civil.

Otro aspecto interesante contenido en el artículo $2^{\circ}$ de la Ley 19.678 es la distinción contenida en el párrafo segundo acerca de la prima y el premio: "La prima es la prestación del tomador o asegurado. El premio incluye la prima más los impuestos, tasas y demás recargos".

Si bien no se detallan los tipos de primas existentes (pura y comercial), lo cual excedería el contenido de una Ley relacionada al contrato de seguros, el concepto final de premio por el cual se inclina el legislador, resulta el adecuado.

\subsection{PERFECCIONAMIENTO DEL CONTRATO}

Otro artículo interesante en este Capítulo general es el artículo 3.

Artículo $3^{\circ}$ (Perfeccionamiento). El contrato de seguro se perfecciona mediante el mero consentimiento de las partes, aún antes de la emisión de la póliza y del pago del premio. 
Cuando el texto de la póliza difiera del contenido de la propuesta, la diferencia deberá destacarse en la póliza y se considerará aprobada por el tomador o asegurado si no se reclama dentro de treinta días corridos de haber recibido la póliza.

Esta aceptación se presume sólo cuando el asegurador advierte al tomador o al asegurado sobre el derecho de reclamar por cláusula inserta en forma destacada en el frente de la póliza.

El asegurador deberá informar en forma clara y precisa sobre todas las previsiones contenidas en la propuesta de contratar y en las condiciones generales, particulares o especiales en su caso, a que refiere el artículo 25 de la presente ley. Este deber de informar podrá ser cumplido por un medio electrónico que permita comprobar su recepción o acceso del asegurado, lo cual será constatado en la forma que determine la reglamentación.

Si de un aspecto novedoso debemos hablar, es el cambio en el perfeccionamiento del contrato de seguros respecto a nuestro sistema anterior a la ley, en que el contrato de seguros se perfeccionaba con una solemnidad de escritura y firma.

Hasta antes de la vigencia de la nueva ley comentada, el contrato se perfeccionaba jurídicamente mediante un documento escrito, público o privado denominado póliza de acuerdo al art. 644 del Código de Comercio, la cual debía estar firmada por el asegurador de acuerdo al art 645 en sede de seguros, que se entendía primaba sobre el art 202, en sede general, que exige la firma de ambas partes para perfeccionar el contrato.

En los hechos y práctica comercial en nuestro país, la firma que solemnizaba al contrato de seguros era la del asegurador que entregaba la póliza con su firma estampada y con ello quedaba perfeccionado el contrato de seguro.

El contrato con la nueva Ley, pasa a ser consensual, pero el artículo $3^{\circ}$ in fine, parece confundir los conceptos al exigir que el asegurador deba informar en forma clara y precisa sobre todas las previsiones contenidas en la propuesta de contratar y en las condiciones generales, particulares o especiales en su caso, a que refiere el artículo 25.

Igualmente, con la nueva Ley, el contrato entra en vigencia con la solicitud aceptada, lo cual hace que se adapte el perfeccionamiento del contrato a la realidad práctica y habitual en el país, pero que con el sistema anterior, creaba problemas en justicia pues allí la solemnidad seguía siendo lo vigente, por lo que establecía el Código.

Por lo tanto, se producía una inconsistencia entre la realidad y la normativa, lo cual hoy supera la ley 19.678 con la consensualidad como principio.

\subsection{Contenido de la póliza. Mención al intermediario}

El artículo 25 a que refiere este artículo, dispone lo que la póliza debe contener que son básicamente los datos que hoy consignan las condiciones particulares, además de las condiciones generales, y en su caso, especiales.

La novedad la aporta el artículo 31 que menciona al intermediario, en la única mención a esta figura, en todo el articulado. 
Artículo $31^{\circ}$ (Intermediario). Cuando en la emisión de póliza o su renovación interviniere un intermediario, debe constar su identificación.

Interesante es la mención al intermediario que realiza el artículo 31 pues deja en evidencia la necesidad de legislar sobre esta figura que no existe consagrada en nuestro ordenamiento jurídico. De lo contrario cualquiera podría ser intermediario y figurar en la póliza de seguros siendo que el rol profesional del asesor en seguros es lo deseable.

Por supuesto, es criticable que el artículo mencione al intermediario solamente pues en sentido estricto el intremediario es el corredor de seguros, dejando afuera al agente que es un mandatario del asegurador, no un mero mediador o intermediario que acerca a las partes, asegurado y asegurador.

No obstante, debe entenderse por interpretación analógica que la mención al agente también deberá constar en la póliza.

Esto si el corredor o agente interviene en la celebración del contrato, la mención a "emisión" es errada pues no es necesario que emita para que figure en la póliza sino que lo que debe es haber intervenido en la etapa pre-contractual como asesor, lo cual justifica que se lo identifique.

\subsection{Entrega de la póliza. Plazos y medios}

Relacionado con lo anterior, el artículo 24 establece los plazos de entrega de las pólizas y sus modificaciones o endosos, y los medios para efectivizarla.

Dice el artículo 24:

Artículo $24^{\circ}$ (Entrega de la Póliza). El asegurador, dentro de los primeros treinta días corridos de la celebración del contrato o toda vez que este se modifique, entregará al tomador una póliza debidamente firmada, con redacción clara en idioma español $y$ fácilmente legible, por un medio que permita comprobar su recepción o acceso. La entrega podrá ser cumplida por un medio electrónico, en caso que el asegurado cuente con ello, que permita comprobar su recepción o acceso del asegurado a la póliza, lo cual será determinado por la reglamentación.

La póliza podrá ser firmada por cualquier método admitido por la legislación nacional o por los usos comerciales.

Es decir que el asegurador tiene treinta días corridos desde el celebración del contrato-o sea desde que la solicitud es aceptada-para enviar la póliza al asegurado, lo cual puede ser realizado por un medio electrónico que permita comprobar su recepción o acceso.

También debe enviar la póliza si existen modificaciones en el contrato, por ejemplo a la hora de la renovación del seguro.

Aquí cabe relacionar este artículo 24 con el artículo 3 y con el artículo 6 de la ley.

Recordemos que el artículo 3 establece, en su segundo y tercer párrafo, que: 
Cuando el texto de la póliza difiera del contenido de la propuesta, la diferencia deberá destacarse en la póliza y se considerará aprobada por el tomador o asegurado si no se reclama dentro de treinta días corridos de haber recibido la póliza.

Esta aceptación se presume sólo cuando el asegurador advierte al tomador o al asegurado sobre el derecho de reclamar por cláusula inserta en forma destacada en el frente de la póliza.

O sea que si sumamos los treinta días que tiene el asegurador para enviar la póliza, más los treinta días que tiene el asegurado para reclamar por las modificaciones que el asegurador le advierta en el frente de póliza, tenemos sesenta días corridos, de cierta inseguridad jurídica.

Esto si pensamos por ejemplo, en un siniestro que ocurra el día veintinueve, cuando el asegurado aún no recibió la póliza o el día cuarenta y cinco, cuando el asegurado aún no se manifestó aceptando las modificaciones, el contrato ya está vigente pero el asegurado aún no conoce las condiciones o bien no ha aceptado expresamente los cambios a la propuesta original ¿puede ser excluido ese siniestro?. Seguramente esta incertidumbre dará trabajo a los abogados.

\subsection{Renovación automática o prórroga del seguro}

El otro artículo relacionado, es el artículo 6 sobre Plazos.

Artículo $6^{\circ}$ (Plazo). Si no se expresa en la póliza otro distinto, el período del seguro será de un año, salvo que por la naturaleza del riesgo corresponda una vigencia diferente. La cobertura tendrá efecto desde el perfeccionamiento del contrato hasta la hora veinticuatro del último día del plazo establecido en el contrato.

Las partes podrán convenir la renovación automática o la prórroga del seguro con antelación a la fecha de vencimiento del plazo, bastando con una constancia del asegurador en la póliza vencida o haciéndolo constar en instrumento separado, salvo que se pretenda modificar las condiciones vigentes en cuyo caso deberá recabarse el consentimiento expreso del tomador. No mediando aceptación de las modificaciones, el contrato se dará por finalizado al vencimiento previsto.

Si se pactara la prórroga o renovación automática, cualquiera de las partes podrá dejarla sin efecto mediante una notificación escrita a la otra parte, efectuada con un plazo de treinta días corridos de anticipación a la conclusión del período del seguro en curso.

El pago del premio o de la primera cuota implicará aceptación de su importe. La reglamentación podrá establecer otras modificaciones que no requerirán el consentimiento expreso del tomador.

Aquí el tema a destacar es la renovación automática o la prórroga de seguro que pueden convenirse, pactarse, antes de la fecha de vencimiento de vigencia del seguro.

Ante esto se pueden dar dos situaciones. Si no existen modificaciones contractuales, entonces basta con hacer constar la renovación o prórroga en la póliza o en un endoso o documento por separado, como dice la norma. 
Ahora bien si existen modificaciones en el contrato a renovar o prorrogar, entonces se debe recabar el consentimiento expreso del asegurado a dichas modificaciones. Si no se recibe dicho consentimiento el seguro finaliza a la fecha de vencimiento previsto originalmente.

En el párrafo final, la norma exceptúa de la necesidad de solicitar el consentimiento del asegurado únicamente cuando exista modificación del premio, siempre que el asegurado pague dicho-nuevo- premio o la primera cuota, lo cual supone aceptación de su importe.

También abre la posibilidad que se establezcan otras modificaciones que no requieran el consentimiento expreso del tomador del seguro a determinar en la reglamentación, que en este punto se vuelve importante para agilitar los mecanismos de renovación o prórroga del seguro.

\subsection{Pluralidad de seguros}

Otra novedad interesante que aporta la ley es para el caso de pluralidad de seguros. En efecto el artículo 9 aporta una solución para el caso que el tomador de un seguro contrate un seguro sobre los mismos riesgos con más de un asegurador, con vigencia coincidente en todo o en parte.

En este caso, el asegurado debe informarlo a cada asegurador al momento de la contratación, indicando el asegurador y la suma asegurada. En ese caso los seguros no son inválidos sino que los aseguradores concurrirán al pago de la indemnización en proporción a la suma asegurada y hasta la concurrencia de la indemnización debida, salvo que se pacte otra cosa en la póliza.

Si ocurriera que un asegurador abonara una suma mayor a lo que proporcionalmente tiene a su cargo, tiene acción contra los demás aseguradores para efectuar el correspondiente ajuste y contra el asegurado en caso que hubiera recibido una indemnización mayor a la debida. De esta forma se respeta el principio indemnizatorio y se evita el enriquecimiento sin causa del asegurado.

Se exceptúan los seguros de personas salvo que se establezca expresamente en la póliza que deben informar sobre la existencia de otros seguros. Esto es lógico pues en los seguros de vida no rige el mentado principio indemnizatorio, al menos en la visión mayoritaria de la doctrina.

La solución aportada por el artículo 9 es novedosa con respecto a la que daba el Código de Comercio. De acuerdo a este, el principio era la prohibición de hacer dos seguros sobre los mismos riesgos en vigencias coincidentes. En caso de que igualmente existiera pluralidad de seguros solo era válido el primero.

El artículo 641 del Código establecía: "No se puede, so pena de nulidad del segundo contrato hacer asegurar segunda vez por el mismo tiempo y los mismos riesgos, cosas cuyo entero valor se hubiere ya asegurado, salvo los casos previstos en este Código (artículo 659 y 665). 
No comprendiendo el primer seguro el valor íntegro de la cosa, o si se hubiese verificado con excepción de alguno o algunos riesgos, subsistirá el seguro en la parte o en los riesgos no incluidos."

La excepción la aportaba el artículo 659, en caso de renuncia del primer seguro, podría volver a asegurarse, y el 665 que en realidad reafirma que el seguro válido en principio es el primero. Artículo 665: "Es lícito asegurar de nuevo una cosa ya asegurada por su valor íntegro en todo o en parte, bajo condición expresa de que no podrá hacer valer sus derechos contra los aseguradores, sino en cuanto no pueda indemnizarse del primer seguro.

En caso de semejante convención, los contratos procedentes deben ser claramente descriptos, so pena de nulidad, y será aplicable la disposición del artículo 663”.

\subsection{Rescisión del contrato}

Respecto a la rescisión del contrato, el artículo 13 de la Ley 19.678 establece que el tomador del seguro podrá rescindir el contrato de seguro en cualquier tiempo, sin expresión de causa, siempre que lo comunique al asegurador en forma fehaciente, con antelación de un mes.

El asegurador en cambio solo podrá rescindir el contrato si media justa causa, también comunicándolo con antelación de un mes al asegurado.

La justa causa es un concepto subjetivo, con todo lo que esto implica, pero el avance que la norma trae es importante pues corrige algunos desvíos actuales en las pólizas que establecen rescisión unilateral para el asegurador, sin expresión de causa.

Lo otro novedoso que el artículo aporta es que establece que en caso de rescisión el asegurador tendrá derecho al cobro del premio por el riesgo corrido durante el periodo transcurrido desde la vigencia del seguro hasta la rescisión.

Nótese que esto es un cambio con respecto a los usos y costumbres actuales en materia de seguros en los cuales en caso de rescisión del tomador, se aplica la llamada tabla de términos cortos o de tarifa, que no se corresponde exactamente con el periodo trascurrido sino que supone una compensación para el asegurador por la rescisión antes del término de vigencia del seguro.

En el caso de seguros de personas, el artículo remite al artículo 104 que es pues el aplicable.

Este artículo 104 establece que el tomador del seguro puede rescindir el contrato luego de la primera anualidad del seguro, salvo pacto en contrario que se justifica pues podría existir un seguro por plazo menor al año.

También estipula que se rescinde el seguro individual en un seguro colectivo cuando el asegurado se desvincula del grupo de afinidad, salvo pacto en contrario, pensando ciertamente en algunas opciones de seguros de vida que dan opciones de continuar con un seguro individual al ocurrir dicha desvinculación. 
En caso de dicha rescisión, el asegurado, dice el artículo 104, tiene derecho al rescate previsto en el artículo 107 de la misma ley. La ley es aquí imprecisa pues está hablando, en el art. 104, del seguro colectivo y remite a un artículo, el 107, que correctamente indica que el derecho de rescate solamente existe en los seguros individuales con reserva matemática. Los seguros colectivos no prevén reserva matemática son de vigencia anual, renovables, por lo tanto no puede dar derecho a rescate de suma alguna.

Recordemos que el derecho de rescate es la posibilidad que tiene el asegurado luego de trascurridos dos o tres años, depende del producto, de solicitar la suma que por derecho a rescate le genera el componente de ahorro en los seguros de vida con reserva matemática, o de supervivencia que generan ese ahorro, que son de vigencias superior al año.

En puridad pues, el derecho de rescate se genera no solo en los seguros dotales o con ahorro sino también en los temporarios (seguro de vida puros o de fallecimiento) mayores a un año, pero en la práctica estos últimos no se comercializan con derecho de rescate.

La norma parece dar dicho derecho al asegurado en todos los casos en que el producto genere reserva matemática, lo cual sería un aspecto a considerar en la modalidad actual de venta de este tipo de seguros.

\subsection{Agravamiento del riesgo}

La Ley trae disposiciones precisas sobre el que llama agravamiento, no agravación, del riesgo, aspecto que no preveía en detalle el Código de Comercio.

El artículo 18 consagra el concepto de agravamiento en forma clásica: constituye agravamiento toda circunstancia que si hubiese existido al tiempo de la celebración del contrato lo hubiera impedido o modificado sus condiciones.

Respecto a la comunicación al asegurador, si el agravamiento se debe a hecho ajeno, el asegurado debe comunicarlo "inmediatamente" de conocerlo y si se debe a hecho propio, antes de que ocurra.

Las excepciones son que se provoque el agravamiento para precaver un siniestro -atenuar sus consecuencias- o por un deber de humanidad generalmente aceptado, aunque persiste la carga de comunicarlo al asegurador (artículo 21).

Los artículos 19 y 20 prevén dos circunstancias: el agravamiento existiendo o no siniestro.

Si existe agravamiento, no existiendo siniestro, si se debe a hecho propio del asegurado, se suspende la cobertura desde que aquel se produce.

Si es por hecho de tercero, se suspende la cobertura desde que es conocida por el asegurado o si lo conoce el asegurador, cuando se lo comunica al asegurado

En ambos casos dentro de los quince días corridos desde que al asegurador le fue declarado el agravamiento del riesgo, el asegurador puede rescindir el contrato con derecho a los premios corridos o acordar modificarlo, es decir ajustarlo al riesgo resultante del agravamiento. 
Si no lo hace en dicho plazo, el contrato se mantiene en las condiciones iniciales.

Si en cambio existe agravamiento y sobrevienen un siniestro, el asegurador queda liberado de su prestación siempre que el siniestro fuera provocado por hecho o circunstancias agravantes del riesgo que no fueron denunciadas

Aquí existe un tema terminológico importante que puede dar lugar a cuestionamientos futuros, pues provocar no es igual a causar.

Provocar es producir o causar algo y producir es procurar, originar, ocasionar. Por lo tanto, podría la norma referir a alguna circunstancia agravante que no fuera la causa del siniestro, pero sí que contribuyera al mismo, que podría dar lugar a la no indemnización o prestación de parte del asegurador.

En el caso de los seguros de personas, el aplicable será el artículo 102 que determina que solo se puede alegar agravamiento por los motivos previstos en la póliza.

\subsection{Plazos para denuncia del siniestro y otros}

Otra novedad importante es que la ley determina plazos para la denuncia del siniestro, para aportar los elementos para la liquidación del daño, para aceptar o rechazar el siniestro y para el pago de la prestación.

Esto es muy importante pues de ahora en más esos plazos serán uniformes, iguales para todos los seguros y aseguradores, salvo como hemos dicho que se pacten plazos más beneficiosos para el asegurado.

A efectos de dejar esto claro, incluyo a continuación un cuadro que determina estos plazos y las consecuencias de incumplirlos.

Los artículos involucrados en estos plazos son el 34, 35, 36, 39 y la sección IV sobre el incumplimiento.

\begin{tabular}{|c|c|c|c|}
\hline PLAZO DE DENUNCIA & $\begin{array}{l}\text { PLAZO PARA INFORMAR } \\
\text { CUANTIA DE DAÑOS }\end{array}$ & $\begin{array}{l}\text { PLAZO DE ACEPTACIONO } \\
\text { RECHAZO DE SINIESTRO }\end{array}$ & PLAZO PARA EL PAGO \\
\hline $\begin{array}{l}\text { informar ocurrencia = inmediatamente } \\
\text { formalizar denuncia }=5 \text { dias } \\
\text { SALvO automotoresa formalizar } \\
\text { inmediatamente }\end{array}$ & 15 días corridos & 30 dias corridos & 60 días corridoe, \\
\hline $\begin{array}{l}\text { desde siniestro o conocimiento de } \\
\text { Ainiestro }\end{array}$ & $\begin{array}{l}\text { sigulentes al siniestro } \\
\text { por escrito al asegurador, salvo dispensa } \\
\text { por escrito del asegurador, }\end{array}$ & $\begin{array}{l}\text { a contar de la recepción de la respectiva } \\
\text { denuncia }\end{array}$ & $\begin{array}{l}\text { a contar de la comunicación } \\
\text { fehaciente al asezurado de la } \\
\text { aceptación del siniestro por parte del } \\
\text { asecurador, } \\
\text { o de vencido el plazo previsto por el } \\
\text { articulo } 35 \text { (ACEPTACION TACITA) }\end{array}$ \\
\hline $\begin{array}{l}\text { Asegurado: incumplimiento de estas } \\
\text { Cargas solo es excusable por causa } \\
\text { extraña no imputable. } \\
\text { Asegurador: no podrk exonerarse de la } \\
\text { responsabilidad al, dentro del miamo } \\
\text { plazo: } \\
\text {-interviene en las operaciones de } \\
\text { salvamento o de comprobación del } \\
\text { siniestro. LO REPITE EL. ART III }\end{array}$ & 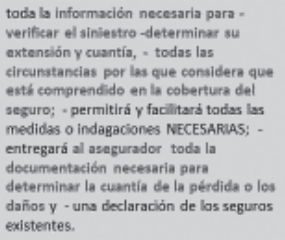 & $\begin{array}{l}\text { salvo = se suspenderá en los casos en que ol } \\
\text { aseguradot, por razones ajenas a su alcance y } \\
\text { voluntad, no contara con los elementos } \\
\text { suficientes para determinar la cobertura del } \\
\text { siniestro }\end{array}$ & $\begin{array}{l}\text { siempre que se haysan cumplida las } \\
\text { obligaciones y cargas previstas por la } \\
\text { presente Ley. }\end{array}$ \\
\hline PIERDE INDEMINIZACION : ART 48 & $\begin{array}{l}\text { PIERDE INDEMNIZACION SALVO CAUSA } \\
\text { EXTRAÑA O FUERZA MAYOR ART } 49\end{array}$ & Vencido el cual se lo tendrá POR ACEPTADO. & $\begin{array}{l}\text { Asegurador CAERÁ EN MORA por el } \\
\text { sollo vencimiento del término, y } \\
\text { correrán intereses moratorios }\end{array}$ \\
\hline
\end{tabular}




\subsection{Prescripción. Registro de Seguros de Vida}

Desde la vigencia de la nueva Ley, los plazos de prescripción cambian.

Ya no será aplicable el artículo 1021 del Código de Comercio que preveía un año de plazo de prescripción tanto para seguros generales como para seguros de personas, a contar desde que la obligación se hacía exigible. Cuando la obligación se hacía exigible y comenzaba a computarse el plazo, fue un aspecto muy discutido en doctrina y jurisprudencia aunque mayoritariamente se interpretaba que era desde el rechazo del siniestro.

La ley distingue ambos plazos y determina más claramente desde cuando se computan.

Para seguros generales serán dos años desde que se comunica al asegurado la aceptación o el rechazo del siniestro o se cumple el plazo del artículo 35, aceptación tácita del siniestro que se produce a los treinta días corridos desde la denuncia sin que el asegurador se expida sobre si acepta o no el siniestro en cuyo caso se tiene por aceptado.

En el caso de seguros de vida, el plazo es de cinco años a contar desde que el beneficiario conoce la existencia del beneficio, aunque siempre cinco años máximo contados desde el fallecimiento del asegurado. En suma, cinco años desde dicho fallecimiento.

Aquí es importante destacar que la ley prevé en su artículo 132, la creación de un Registro de seguros de vida a cargo del Banco Central del Uruguay donde la persona que cree ser beneficiario de un seguro de vida puede consultar con la partida de defunción del asegurado.

Allí le informarán si éste tenía un seguro de vida y en qué empresa aseguradora, donde podrá consultar en definitiva si es el beneficiario.

Esto genera una carga importante a los aseguradores que deben informar al BCU todos los seguros de vida que suscriban con el nombre de tomador del seguro. Además si transcurren cinco años sin que nadie reclame el beneficio, las aseguradoras deberán volcar el capital asegurado, dentro de los diez días de vencido el plazo de prescripción de cinco años, a la cuenta Tesoro Nacional bajo el rubro "Seguros de Vida no reclamados", lo cual puede redundar en una suba de premios en los seguros de vida pues los aseguradores hasta ahora no debían volcar dichos montos no reclamados.

En virtud de la remisión a otra normativa que realiza la ley, quienes resulten legitimados podrán reclamar los fondos al Tesoro Nacional por un período de diez años.

\subsection{Disposiciones sobre ramas y tipos de seguros}

En el Capítulo II la ley se explaya sobre disposiciones generales aplicables a los seguros de daño a los que llama de daños patrimoniales. Esta nomenclatura no es la más feliz pues los seguros de daño patrimonial en sentido estricto son los seguros de responsabilidad civil en los que el riesgo cubierto es el eventual daño patrimonial que el asegurado puede sufrir al dañar o perjudicar a un tercero, y ante su reclamo. 
Obviamente aquí la Ley utiliza el concepto de seguros de daño patrimonial en sentido genérico abarcando todo los tipos de seguros de daño o seguros generales.

A nuestros efectos, referiré muy brevemente a las distintas ramas de seguros de daño que la ley regula.

En las diversas secciones de este Capítulo II, la ley establece previsiones sobre las siguientes ramas de seguros

- $\quad$ seguros de incendio, recoge lo que usualmente se preveía ya en las pólizas más modernamente que lo dispuesto en el Código de Comercio, aportando un definición de incendio

- $\quad$ seguros de responsabilidad civil, una novedad absoluta su regulación pues el Código de Comercio, por un tema lógico de antigüedad no los previa. Aquí destaca la prohibición de la acción directa del tercero contra el asegurador-aspecto polémico y no compartible en mi opinión-, la aceptación de la cobertura en base a reclamos hechos o claims made, los deberes de colaboración del asegurado y la defensa en juicio del asegurado si esta se pacta, o sea eventual no obligatoria.

- $\quad$ seguro de hurto, nótese que no refiere a seguro de robo sino de hurto dice la ley, lo cual puede hacer confundir el seguro de robo con la figura penal del hurto, cuando en realidad no deben relacionarse.

- $\quad$ seguros de transporte, se establece la aplicación subsidiaria de las disposiciones del Código de Comercio en materia de seguros marítimos en una técnica legislativa poco compartible, y se dejan fuera los seguros aeronáuticos que se regirán por el Código aeronáutico

- $\quad$ seguros de riesgo agrícola, destaca aquí la previsión de los seguros por índices o paramétricos.

Luego, el capítulo III se dedica los seguros para las personas destacando, además de los aspectos antes reseñados, la posibilidad, ya prevista por el Código de Comercio de asegurar la vida de un tercero sin noticia siempre que exista interés asegurable, la previsión de un artículo referido a las cláusulas de enfermedades preexistentes que supone un gran avance en el sentido de que recoge lo que la jurisprudencia ha venido diciendo sobre las mismas -dado que al inicio eran demasiado amplias--, la regulación detallada de la designación de beneficiarios, la previsión de que el concurso del tomador, asegurado o beneficiario no afecta al contrato de seguros, entre otros.

\section{OTRAS DISPOSICIONES}

\subsection{Reaseguros (capitulo IV)}

La ley dedica cinco artículos a los reaseguros, destacando la posibilidad de pactar la cláusula cut through, por la cual el asegurado podría reclamar directo al reasegurador el pago de la indemnización. 
Esto reconoce que en nuestro país el uso de la figura del fronting es común, incluso con cesión del cien por ciento del riesgo al reasegurador, por lo cual puede ser útil pactar dicha cláusula, pues en la realidad el reasegurador, en un fronting, es quien determina las condiciones del seguro.

\subsection{Reglas de derecho internacional privado (capitulo V)}

La ley determina aplicable en forma imperativa al contrato de seguros la ley del lugar de cumplimiento de la prestación característica que se entiende es el lugar de domicilio de la sucursal agencia u oficina de la aseguradora que celebró el contrato y emitió la póliza o dónde estén situados los bienes muebles o inmuebles objeto del seguro.

En definitiva, será la ley uruguaya la aplicable en la generalidad de los casos pues la reserva de mercado nacional determina que los riesgos que acaecen en el país deben ser cubiertos por empresas debidamente instaladas, autorizadas y habilitadas a la cobertura de riesgos en el país.

Para reaseguros es posible pactar otra legislación aplicable.

La jurisdicción competente en contratos de seguros es la del Estado cuya ley es aplicable conforme con lo antedicho.

\subsection{Denominación de empresas de seguros (capitulo VI)}

Se trata de una norma ya existente en el decreto reglamentario de la Ley 16426 , Decreto 354/94, con nueva formulación y con la previsión de sanciones para el caso del uso de expresiones que refieran a la actividad aseguradora o reaseguradora en la denominación social de empresas no aseguradoras ni reaseguradoras, que puedan inducir a equívocos sobre su naturaleza y responsabilidad patrimonial o administrativa.

Esto pues la palabra seguro conlleva un respaldo sustentado en la solvencia patrimonial, reservas técnicas, buena administración y contralor estatal que avalan su estabilidad ante los consumidores.

\subsection{Temas técnicos (capitulos VII y IX)}

Los capítulos VII sobre activos y reservas en materia de obligaciones previsionales, así como el capítulo IX sobre seguros de accidentes de trabajo y enfermedades profesionales, son típico ejemplo de cómo el legislador aprovecha la ocasión de legislar en seguros, para dar rango legal y aportar soluciones a aspectos técnicos de los seguros previsionales y los seguros de accidentes de trabajo.

\subsection{Seguro Obligatorio automotor - SOA (capitulo VIII)}

Aquí la ley sustituye el artículo 22 de la Ley 18.412 de SOA, determinando que el procesamiento de los reclamos por coberturas especiales queda ahora en manos de 
la UNASEV (Unidad nacional de seguridad vial) y ya no de la Superintendencia de Servicios Financieros como hasta ahora.

Será la UNASEV la que asignará una aseguradora en el caso de reclamos por coberturas especiales, o sea cuando el asegurado o sus causahabientes soliciten se les asigne una aseguradora ante casos de víctimas de automotores sin seguro, que se den a la fuga o hurtados u obtenidos con violencia.

Dicha adjudicación de casos a las aseguradoras será realizado en proporción a las coberturas de automotores, en todas sus formas y categorías comercializadas anualmente por las aseguradoras. Este es un cambio de criterio pues la ley de SOA establecía que dicha asignación sería en base a los seguros obligatorios, no a toda la cartera de automotores. Luego la Superintendencia cambió el criterio, aplicando el que trae ahora la ley. ${ }^{4}$

\subsection{Base de datos (capitulo $X$ )}

La ley autoriza a las empresas aseguradoras a establecer bases de datos comunes que contengan datos para la liquidación de siniestros y la colaboración estadístico actuarial y para para la prevención del fraude en seguros

El problema es que no exime de la necesidad de solicitar, como si preveía en anteproyectos anteriores, el consentimiento del asegurado, lo cual puede llegar a ser un problema de antiselección, pues los fraudulentos difícilmente acepten, den su consentimiento para que sus datos sean introducidos en una base de datos de seguros para combate al fraude, en cambio quienes no tengan la intención de defraudar si lo harán, volviendo dicha base ineficiente.

Luego se prevé el Registro de seguros de vida al cual ya he referido.

\subsection{Derogaciones y sustituciones. Reserva de mercado (capitulo XI)}

La ley establece que quedan derogadas todas las disposiciones que se opongan a ella, en una técnica poco compartible porque puede dar lugar a dudas sobre si algunos artículos del Código de Comercio, o de otras leyes relacionadas a la actividad, quedan derogados o no.

Seguidamente el artículo 134 sustituye el artículo 2 de la Ley 16.426 que es el que establece la reserva de mercado, es decir que los riesgos que puedan acaecer en el Uruguay deben ser cubiertos por seguros otorgados por empresas autorizadas a operar en el país.

\footnotetext{
4 Lo cual hizo por resolución, no por ley, lo que dio origen, en su momento, a recursos administrativos de parte de varias aseguradoras privadas.
} 
No trae grandes modificaciones con respecto a la reserva en si, aunque si aclaraciones en el texto sobre todo en las excepciones a dicha reserva.

Novedoso, si es la inclusión en dicha reserva en forma expresa de los seguros de crédito a la exportación cuando la exportación se efectúe desde territorio nacional -a contrario sensu si se trata de dichos seguros por importación no necesitan seguro nacional- y la definición de buque mercante-cuyos seguros son una excepción a la reserva de mercado, es decir se pueden contratar con empresas extranjeras- que aporta el inciso final.

Esta definición de buque mercante, como "toda construcción flotante, autopropulsada o no de carácter civil, cuya finalidad sea el transporte de bienes o personas con propósito mercantil en el ámbito marítimo, fluvial y lacustre", deja dudas sobre la situación de algunas embarcaciones que no tienen por objeto el traslado de bienes o personas a pesar de tener finalidad comercial, como ser los buques pesqueros y los remolcadores.

Si leemos en forma literal la definición, este tipo de embarcaciones deberían contar con seguros nacionales, lo cual altera la práctica por ejemplo, en el caso de los remolcadores que suelen contar con seguros extranjeros.

\subsection{Disposiciones transitorias (capitulo XII)}

Se establece la aplicación inmediata de la ley -debo agregar, salvo cuando esta establece otra cosa, como es el caso del Registro de seguros de vida en que se dio 180 días de plazo para el inicio de su funcionamiento- a los contratos de seguros, y renovaciones, que se celebren con posteridad a su vigencia.

Esto significa que la Ley fue de inmediata aplicación, con lo cual no se dejó un plazo de carencia de aplicación como suele suceder en este tipo de leyes que requieren modificaciones contractuales, en los textos de las pólizas.

De toda formas, el mercado nacional de seguros ha reaccionado en debida forma ante esta inmediata aplicación, y ha venido adaptando las pólizas en forma paulatina, con la colaboración del órgano de contralor de la actividad la Superintendencia de servicios financieros que ha fijado plazos razonables para la presentación de los nuevos cláusulados.

\section{BIBLIOGRAFÍA}

Bataller Grau, J. La necesaria tipificación de nuevos contratos de seguro: servicios y smarts contracts -Temas de derecho de seguros y reaseguros- Universidad de Montevideo - En edición.

Signorino Barbat A. Derecho de seguros Ley 19678 de 26/10/2021 de Contrato de Seguros -Comentada y anotada- La Ley Uruguay-Thomson Reuters -Montevideo- 2019. 
